ELISA whose result are expressed as the difference of OD values given by sera tested against the citrullinated and non-citrullinated forms of filaggrin were tested at entry.

Results Characteristics of these markers for RA are reported in the Table 1. Specificity of ACRFA was better than that of RF, APF and to a lesser degree AKA. Sensitivity of ACRFA was higher than that of AKA which is the single test still routinely used for detection of AFA. AKA, APF and ACRFA were complementary since certain sera were positive for only one test. Only 5/48 (10.5\%) RF-negative RA patients were positive for ACRFA.

\begin{tabular}{|c|c|c|c|c|}
\hline & Sensitivity & Specificity & $\begin{array}{l}\text { Positive predictive } \\
\text { value }\end{array}$ & $\begin{array}{l}\text { Negative predictive } \\
\text { value }\end{array}$ \\
\hline $\begin{array}{l}\text { FR- } \\
\text { IgM }\end{array}$ & 45.4 & 92.1 & 88.8 & 55.1 \\
\hline AKA & 23.8 & 95.3 & 87.5 & 47.6 \\
\hline APF & 34.1 & 92.1 & 85.7 & 50.4 \\
\hline ACRFA & 30.7 & 98.4 & 96.4 & 50.8 \\
\hline
\end{tabular}

Conclusion AFA detected by a new ELISA have a higher diagnostic value for RA than AFA identified by previous tests in this population-based cohort of very early arthritis.

Study granted by the Fondation de la Recherche Médicale (FRM), the Association de Recherche sur la Polyarthrite (ARP) and for clinical assessment Pharmacia-Searle, France.

\section{THU0167 CORRELATIONS BETWEEN THE PRESENCE OF RF, CRP AND AAF AND THE DIAGNOSIS AND PROGRESSION OF RA}

M Popa, D Stratan. Rheumatology, Rehabilitation Hospital, lasi, Romania

10.1136/annrheumdis-2001.1069

\section{Background}

Objectives The aim of the study is to demonstrate the important role played by rheumatoid factor $(\mathrm{RF}), \mathrm{C}$ reactive protein (CRP) and anti-philaggrin antibodies (APA) in the early diagnosis and in the follow-up of rheumatoid arthritis (RA).

Methods Twelve patients were included in our study, all in an early stage of the disease, accomplishing the ARA criteria for the classification of RA. We tested the levels of RF, CRP and APA and we evaluated on the $\mathrm{X}$-ray the erosions according to the Larsen score.

Results The RF was present in $80 \%$ of the cases while CRP was present in $100 \%$ and APA only in 38\%. However the APA have a specificity of $100 \%$ for RA and a strong correlation with the presence of HLA DR1. The high levels of RF and CRP are best associated with the presence and progression of the erosive lesions, the presence of the rheumatoid nodules and of the systemic involvement. CRP can be considered as a very good prognosis factor in the follow-up of RA.

Conclusion RF and CRP are highly important factors in assessing of the evolutivity of the radiological lesions and in the follow-up of RA, while APA have a high specificity for RA and their presence is less correlated with the severity of the disease and more with an early diagnosis, before the ARA criteria of classification would be fulfilled.

\section{THU0168 CORRELATION BETWEEN SF36 AND INDICES OF OUTCOME IN 121 RHEUMATOID ARTHRITIS (RA) PATIENTS}

MC Lunic, MB Nishishinya, S Galceran, G Nasswetter. Rheumatology, Hospital Escuela "Jose de San Martin", Universidad de Buenos Aires, Buenos Aires, Argentina

10.1136/annrheumdis-2001.1070

Background The SF36 is a generic 36 items questionnaire which measures eight dimensions of health status, and permit to make direct comparisons with other disease states or with population norms. SF36 reflects a combination of physical and mental function, and well-being, the extent of social and role disability, and patients personal evaluation of health status. It has been used in several countries and its contents and construct validity, test retest reliability and responsiveness have also been reported.

Objectives to evaluate the health related quality of life (HRQoL) of patients affected by rheumatoid arthritis (RA) through SF36, and to correlate the results with ACR core set activity index and with mHAQ disability index.

Methods The study included 121 consecutive patients affected by RA attending the "Hospital de Clinicas", mean age 50(18-84) years, mean disease duration 91(3-480) months, erythrocyte sedimentation rate (ESR)34.71(8-105) $\mathrm{mm} / \mathrm{h}$, and mean mHAQ 0.68(0-3). The HRQoL was evaluated through SF36(100-0) eight domains, physical function (PF), physical role (PR), bodily pain (BP), general health $(\mathrm{GH})$, vitality $(\mathrm{V})$, social function (SF), emotional role (ER), and mental health $(\mathrm{MH})$. Disease activity was assessed using ACR core set, swollen joint count (SJcount 028 ), tender joint count (TJ count $0-28$ ), pain by visual analogue scale (VAS 0-100), patient global assessment by VAS, physician global assessment by VAS, acute phase reactant erythrocyte sedimentation rate (Westergren, $\mathrm{mm} / \mathrm{h}$ ), and disability by $\mathrm{mHAQ}(0-$ 3).

Results The mHAQ showed good correlation with $\mathrm{PF}, \mathrm{BP}(\mathrm{r}>$ $0.61), \mathrm{SF}(\mathrm{r}>0.55)$, and correlated with $\mathrm{PR}, \mathrm{V}(\mathrm{r}>0.47)$. VAS pain correlated well with $\mathrm{BP}$ and $\mathrm{V}(\mathrm{r}>0.60)$, and correlated with PF, PR, and $\mathrm{GH}(\mathrm{r}>0.41)$, patients global assessment correlated with $\mathrm{BP}, \mathrm{GH}, \mathrm{V}(\mathrm{r}>0.48)$. All correlations had $\mathrm{p}<0.001$. Conclusion SF36 showed to be a practical tool for use in RA patients and may facilitate to achieve burden of impact of disease and to compare with that of other chronic diseases. In this cohort mHAQ was significantly associated with physical and social function as well as bodily pain and vitality. VAS patients global assessment was associated with general health, vitality and bodily pain. No correlation were found with physical and mental role suggesting that different information is involved. Differences with others RA cohorts may be due to demographic characteristics and medical conditions in our group.

\section{THU0169 EARLY RHEUMATOID ARTHRITIS(ERA) IN THE ASPECT OF DIFFERENTIAL DIAGNOSIS}

AF Filipowicz-Sosnowska, MP Przygodzka, JZ Zabek. Rheumatology Clinic, Institute of Rheumatology, Warsaw, Poland

\subsection{6/annrheumdis-2001.1071}

Background Difficulty in the diagnosis of early rheumatoid arthritis (ERA) in the aspect of differential diagnosis.

Objectives The diagnosis of rheumatoid arthritis (RA) is based on ACR criteria, which are clinical, radiological and immunological. During the first month after onset the diagnosis is often difficult because of a frequently ?atypical? presentation and a lack 
of radiological changes. Rheumatoid factor has low specify and is often negative in ERA. The other non-rheumatological disorders (viral infection, neoplastic and endocrine diseases) may also in the early stage present like RA symptoms.

The objective of this study was to revised the preliminary diagnosis of ERA in hospitalised patient.

Methods Clinical examination (including laboratory tests and $\mathrm{X}$ ray), immunological tests: RF, antikeratin antibodies (AKA).

Results During the last 26 month 510 RA patients (according ACR criteria) were hospitalised in Rheumatology Department. Among this group of patients $94(18 \%)$ were admitted with the preliminary diagnosis ERA. All of this patients group fulfilled the first four clinical ACR criteria The duration of the disease was varied 3 to 9 months. All patients were carefully examined according number of painful and swollen joints, their symmetry and localisation, presence of RF, AKA antibodies and radiological erosions. In cases were RA diagnosis was doubtful other needful examination were done. The diagnosis of ERA was established in $48(52 \%)$, but in 46 (48\%) was excluded. ERA patients were predominately women, symmetrical polyarthris of the hands was present in $45(52 \%)$. RF in $28(58 \%)$, radiological erosions were found in $5(10 \%)$. In group of patients with excluded ERA the following diagnosis was established: osteoarthritis 14 (31\%), RA ? like (nonclassified) $13(28 \%)$, reactive arthritis 3(7\%), hepatitis viral infection 2 (4\%), neo 2 (4\%), Hashimoto syndrome 5 (11\%), Sjogren syndrome 2 (4\%), Polymialgia 2 (4\%), Fibromialgia $3(7 \%)$. AKA were present in $30(62 \%)$ patients in group with established diagnosis of RA and RF was present in 28 $(58 \%)$ patients in this group. AKA was present in $10(21 \%)$ patients with different diagnosis and RF was observed in 8 $(17 \%)$ patients in this group.

Conclusion 1) ACR criteria are insufficient in aspect of differential diagnosis of ERA and non ERA. 2) Present RF and AKA are more specific in ERA than in non ERA patients.3) The diagnosis of ERA should be established by specialists.

\section{REFERENCES}

1 Hassfeld W, Steiner G, Graninger W, Witzmann G, Schweitzer $H$, Smolen JS. Autoantibody to the nuclear antigen RA 33: a marker for early RA. Br J Rheumatol. 1993;32:199-203

2 Paimela L, Gripenberg M, Kuski P, Leirisalo ? Repo M. Antikeratin antibodies: diagnostic and progostic markers for early rheumatoid arthritis. Ann Rheum Dis. 1992;51:743-6

\section{THU0170 IMMUNOGLOBULIN G FC-RECEPTOR (FCGR) IIIA POLYMORPHISMS AND DISEASE EXPRESSION IN RHEUMATOID ARTHRITIS}

${ }^{1} \mathrm{JG}$ Brun, ${ }^{1} \mathrm{TM}$ Madland, ${ }^{2} \mathrm{CA}$ Vedeler. ${ }^{1}$ Department of Rheumatology; ${ }^{2}$ Department of Neurology, Haukeland University Hospital, Bergen, Norway

10.1136/annrheumdis-2001.1072

Background $\mathrm{Fc}$ receptors for $\mathrm{IgG}(\mathrm{Fc} \gamma \mathrm{R})$ modulate immune responses. Fc $\gamma$ receptors are expressed on various leukocytes and contain allelic polymorphisms with different capacity for IgG binding and phagocytosis. The Fc $\gamma \mathrm{R}$ polymorphisms have been implicated as genetic factors that may influence the susceptibility to autoimmune disease. FcyRIII has two isoforms (A and B) and is encoded by genes on chromosome 1. For FcrRIIIA, the presence of the valine $(\mathrm{V})$ allele confers a higher receptor affinity for IgG1, IgG3 and IgG4 than does the presence of the phenylalanine $(\mathrm{F})$ allele.
Objectives We investigated the distribution of the FcyRIIIA alleles in rheumatoid arthritis (RA), and whether they were related to disease expression and severity.

Methods Ninety-six controls and 114 patients fulfilling ACR criteria for RA were genotyped for FcyRIIIA polymorphisms using PCR. Physician's global assessment of RA type estimated RA disease expression. In addition, usual measures of disease activity were recorded.

Results Crosstabulation of the FcyRIIIA genotypes V/V and V/F combined vs the F/F genotype showed that more patients with aggressive RA than expected had the $\mathrm{V} / \mathrm{V}$ and $\mathrm{V} / \mathrm{F}$ genotypes ( $\mathrm{P}$ $<0.05)$. The Fc $\gamma$ RIIIA V/F genotype and the V allele was slightly more frequent among RA patients than among controls. This finding however, was not statistically significant. We found no significant associations with the clinical and laboratory variables of disease activity.

Conclusion The results of previous studies regarding Fc $\gamma$ RIIIA in RA are not consistent. The present findings of a more severe disease among patients homo- and heterozygous for the valine (V) allele, and the suggested tendency of more than expected $\mathrm{V} / \mathrm{V}$ and V/F genotypes among RA patients as compared to controls, lend support to the notion of FcyRIIIA as a possible disease susceptibility and disease-modifying gene in RA.

\section{THU0171 A CLINICAL RELEVANT INCREASE IN RADIOLOGICAL PROGRESSION, THE PATIENT'S PERSPECTIVE}

PM Welsing, AM Van Gestel, HL Swinkels, PL Van Riel. Department of Rheumatology, University Medical Centre Nijmegen, Nijmegen, The Netherlands

\subsection{6/annrheumdis-2001.1073}

Background Radiological progression is considered the most important outcome for Rheumatoid Arthritis, but there is no established definition, as to what constitutes a clinical important progression of joint damage. The smallest detectable difference (SDD) for the modified Sharp method and the Larson method was taken as a starting point. And expert opinion of rheumatologists was used to determine the clinical relevant progression. However these findings might not reflect the true clinical important progression in radiological damage. The clinical important difference should be the effect this progression has on the patient, being the development of physical disability.

Objectives To estimate the clinical relevant increase in radiological damage, using the effect on physical disability.

Methods This study elaborates on the findings of studies, investigating the clinical relevant increase in the HAQ-DI score, and on a study investigating the relation between disease activity, radiological damage, sociodemographic factors, and physical disability. The clinical relevant difference in physical disability (HAQ-DI) has been determined by asking patients to rate themselves relative to another patient, and was estimated to be between 0,2 and 0,3 . The relation between physical disability (HAQ-DI), disease activity (DAS), and radiological damage (Modified Sharp score) was determined, using the follow-up data of 378 patients from an open prospective study of early RA (disease duration < 1 year). Linear regression was used at $0,3,6$, and 9 years after inclusion with as dependant variable the HAQ-DI, and as independent variables, disease activity (DAS), radiological damage, and sociodemographic factors. The main results of this study were that the relation between radiological progression and physical disability was dependent on the activity of the disease and the present radiological damage (5). With higher disease 